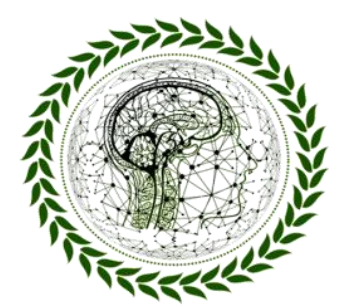

PhID Scientific Review

ISSN 2676 - (1444

Submetido em: 27/12/2021 | Aceito em: 06/01/2022 | Publicado em: 10/01/2022 | Artigo

\title{
ANÁLISE DA MOTIVAÇÃO INTRÍNSECA DE ESTUDANTES DE NUTRIÇÃO EM UMA FACULDADE COM METODOLOGIA ATIVA NO BRASIL
}

\author{
Alícia Natalie Silva dos Santos ${ }^{1}$ \\ Amanda Andrade Furtado 2 \\ Adriana Carla Santos de Menezes Ramos ${ }^{3}$ \\ Enésia Eloyna da Costa Benízio ${ }^{4}$
}

Resumo: A Teoria da Autodeterminação foi desenvolvida, a fim de avaliar os componentes da motivação intrínseca e extrínseca e os fatores relacionados com a sua promoção. A motivação intrínseca é reconhecida como um mediador importante na conquista da competência e autoconceito do indivíduo sobre o ambiente. O objetivo deste estudo foi analisar a motivação intrínseca baseada na Teoria da Autodeterminação nos estudantes de Nutrição de uma Faculdade que utiliza a Aprendizagem Baseada em Problema para a participação no grupo tutorial. Métodos: Foi realizado um estudo de corte longitudinal, analítico com abordagem quantitativa desenvolvido na Faculdade Pernambucana de Saúde (FPS). Participaram da pesquisa os estudantes que estavam cursando do $1^{\circ}$ ao $6^{\circ}$ períodos do curso, regularmente matriculados no período da pesquisa, totalizando 251 estudantes participantes da pesquisa. Foi utilizado o Inventário de Motivação Intrínseca (IMI) como instrumento para análise da motivação no qual foi traduzido, validado e adaptado transculturalmente para o português brasileiro. Resultados: Não houve diferença significativa nas notas (escores médios) por competências comparando os três primeiros períodos $\left(1^{\circ}, 2^{\circ}, 3^{\circ}\right)$ com os três últimos períodos do curso $\left(4^{\circ}, 5^{\circ}, 6^{\circ}\right)$, sendo menor resultado 4,0 e maior resultado 6,0 respectivamente. As médias (escores médios) das subescalas avaliados no final do semestre para todos os períodos $\left(1^{\circ}\right.$ ao $\left.6^{\circ}\right)$ foram: interesse/prazer com a média 5,3; competência percebida 5,3; valor/utilidade 6,1; esforço/importância 5,0; pressão/tensão 4,3; percepção de escolha 4,5; e integração 5,4, classificado em "motivado" >3,0 e < <,0 e $\geq 6,0$ "muito motivado" para a atividade. A motivação intrínseca dos estudantes do $1^{\circ}$ ao $6^{\circ}$ período foram comparados os escores por domínio, no início e final do semestre obtendo resultados interesse/prazer com a média 5,5 e 5,3 respectivamente; competência percebida 5,1 e 5,3 respectivamente; valor/utilidade 6,2 e 6,1 respectivamente; esforço/importância 5,2 5,0 respectivamente; pressão/tensão 4,2 e 4,3 respectivamente; percepção de escolha 5,0 e 4,7 respectivamente; e integração 5,7 e 5,4 respectivamente. Esse trabalho demonstrou que os estudantes de Nutrição se apresentaram intrinsecamente motivados para realizar as atividades no grupo tutorial, no início e final do semestre letivo, tanto nos períodos iniciais quanto nos períodos finais do curso.

Palavras-chave: Aprendizagem Baseada em Problemas (ABP); Inventário de Motivação Intrínseca (IMI); grupo tutorial.

1;2;3 e 4 Bacharéis em Nutrição pela Faculdade Pernambucana de Saúde - FPS.

http://www.revistaphd.periodikos.com.br

V. 02, $\mathrm{N}^{\mathrm{o}}$ 01, janeiro de 2022

DOI: $10.53497 /$ phdsr2n1-001

Todos os direitos reservados(C) 


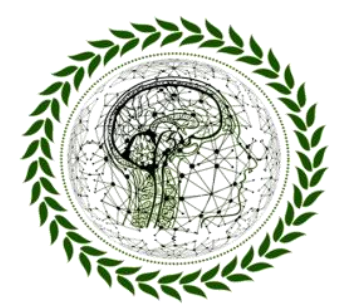

\title{
PhI Scientific Review \\ ISSN 2676 - 0444
}

\section{ANALYSIS OF THE INTRINSIC MOTIVATION OF NUTRITION STUDENTS FROM A COLLEGE WITH ACTIVE METHODOLOGY IN BRAZIL}

\begin{abstract}
The Theory of Self-Determination was developed, in order to assess the components of intrinsic and extrinsic motivation and the factors related to its promotion. Intrinsic motivation is used as an important mediator in the achievement of the individual's competence and self-concept about the environment. The aim of this study was to analyze the intrinsic motivation based on the Theory of Self-determination in Nutrition students from a Faculty that uses Problem-Based Learning to participate in the tutorial group. A cross-sectional, analytical study was carried out with a quantitative approach. Participating in the research were students who were attending the 1st, 2nd, 3rd, 4 th, 5th and 6th periods of the course, regularly enrolled in the research period. The Intrinsic Motivation Inventory (IMI) was used as an instrument for analyzing motivation. There was no significant difference in grades for competences comparing the first three periods (1st, 2nd, 3rd) with the last three periods of the course (4th, 5th, 6th). The averages of the domains evaluated at the end of the semester for all periods (1st to 6th) were: interest / pleasure with the average 5.3; perceived competence 5.3; value / utility 6.1; effort / importance 5.0; pressure / tension 4.3; perception of choice 4,5; and integration 5.4, classified as "motivated" and "very motivated" for the activity. This work demonstrated that the Nutrition students were intrinsically motivated to carry out the activities in the tutorial group, at the beginning and end of the academic semester, both in the initial and final periods of the course.
\end{abstract}

Keywords: Problem-Based Learning (PBL); self-determination; tutorial group.

\section{INTRODUÇÃO}

Tradicionalmente o sistema de ensino é centrado na figura do professor, em outras palavras, o docente é quem possui o conhecimento que deve ser transmitido ao estudante que deve memorizá-lo, ou seja, toda a informação é repassada de forma passivas em haver a necessidade de criticar ou refletir sobre os conteúdos. ${ }^{1,2}$

No contexto social atual, ocorreram mudanças em todos os segmentos: educacional, social, político, econômico e cultural, com espaço para novos conceitos de aprendizado. Assim, a educação precisa subsidiar a resolução de problemas da vida real e as ações educacionais possuem um papel fundamental no desenvolvimento de relações sociais, permitindo o estudante aprender de forma prática e auxiliando no desenvolvimento de suas habilidades. ${ }^{3}$

Diante do exposto, surge a necessidade de metodologias centradas no estudante, em que a autonomia seja incentivada, ou seja, metodologias ativas de aprendizagem. ${ }^{4}$ A metodologia ativa

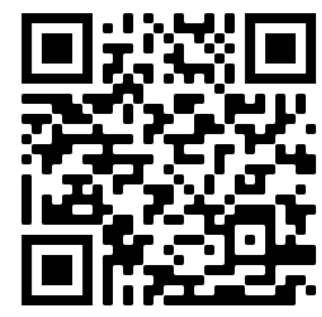

http://www.revistaphd.periodikos.com.br

V. 02, $\mathrm{N}^{\mathrm{o}}$ 01, janeiro de 2022

DOI: $10.53497 /$ phdsr2n1-001

Todos os direitos reservados(C) 


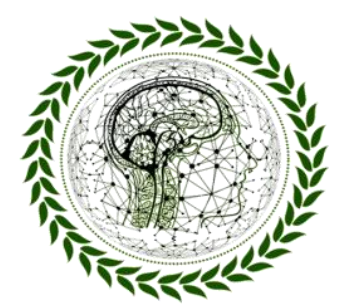

PhI Scientific Review

ISSN 2676 - (144

se caracteriza pela inter-relação entre a educação, cultura, sociedade, política e escola, sendo desenvolvida por meio de métodos ativos e criativos, centrados na atividade do estudante, com a intenção de possibilitar a aprendizagem, baseando-se nas suas experiências e autonomia. ${ }^{5}$

Entre essas metodologias, está a Aprendizagem Baseada em Problemas (ABP) ou Problem Based Learning (PBL). A perspectiva da ABP é delineada nos princípios derivados da psicologia cognitiva, caracterizada como uma forma de aprendizagem e instrução colaborativa, construtivista, contextual e autônoma. A aprendizagem colaborativa se baseia nos estudantes que diante do problema exposto irão trabalhar de forma cooperativa e colaborativa, aprendendo de forma contextualizada, apropriando-se de um saber com significado pessoal, sendo assim, os modelos curriculares da ABP são largamente transdisciplinares e construtivistas na sua natureza, pois é dada a oportunidade aos alunos de construírem o conhecimento, desenvolvendo a autonomia, a visão complexa da realidade, a responsabilidade, a atitude diante dos problemas, para resolvê-los de forma criativa, a habilidade para o diálogo e partilha de ideias em grupo, argumentando de forma sistemática para que a resolução do problema seja satisfatória e eficaz. ${ }^{6,7,8}$

$\mathrm{Na}$ ABP se parte do problema, que deve conter gatilhos para uma boa tempestade de ideias e definição dos objetivos de aprendizagem. Um problema apresentado pode não ter solução, a aprendizagem mediante trabalho em pequenos grupos, utilizando-se de conhecimentos previamente adquiridos, facilitando a apreensão do novo conhecimento e a valorizando o trabalho em equipe. A ABP teve sua primeira implantação no ensino da saúde na Universidade de McMaster, no Canadá, em 1969, trazendo uma proposta pedagógica sólida, baseando na busca de integração entre discentes e docentes, incentivando o pensamento crítico reflexivo acerca das temáticas abordadas. ${ }^{9}$

Atualmente, essa metodologia tem se destacado no contexto educacional, pois representa uma alternativa para a construção do conhecimento em uma sequência organizada e de maneira transversal, encorajando o estudante a aumentar sua capacidade de buscar informações de forma ativa, explorar novas áreas, gerenciando assim seu próprio aprendizado. Além disso, essa metodologia possibilita ao estudante a oportunidade de trabalhar suas habilidades de 


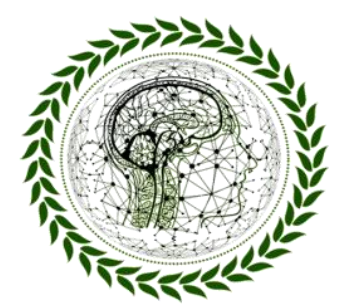

PhI Scientific Review

ISSN 2676 - (144

comunicação e também a competência crítica e argumentativa, estimulando o estudante na busca por conhecimento. ${ }^{10}$

Por outro lado, já é conhecido que o processo de motivação do estudante em busca de novos conhecimentos e novas descobertas tornaram-se objeto de pesquisa e investigação por psicólogos e educadores. O estudo da motivação representa a busca de explicações para o comportamento humano para determinadas ações e vem se ampliando rapidamente nas últimas décadas, sendo assim o método ABP estimula a autonomia e a proatividade, no qual, o estudante precisa estar bastante motivado, sobretudo intrinsecamente. ${ }^{11}$ Existem diferentes teorias que tratam da motivação, destacando-se a Teoria da Autodeterminação (TAD) ou Self-Determination Theory (SDT), que considera que a motivação pode produzir efeitos no comportamento do indivíduo e que essas consequências podem interferir na motivação. ${ }^{9} \mathrm{Na}$ teoria da autodeterminação são feitas diferenciações baseadas nas razões ou objetivos que originam a ação entre os diferentes tipos de motivação. ${ }^{12}$

A diferenciação mais básica é entre motivação extrínseca, que se refere a fazer algo esperando um resultado, e motivação intrínseca, que se refere a fazer algo porque é inerentemente interessante. Essa última é caracterizada como uma forma natural de aprendizagem e realização, que pode ser sistematicamente afetada pelas práticas dos pais e professores. ${ }^{13}$ Dessa forma, as atividades motivadas intrinsecamente são caracterizadas por não terem uma recompensa aparente, o que leva a concluir que a motivação intrínseca se encontra associada à realização pessoal ou ao trabalho em si. ${ }^{14}$

Relacionado à motivação extrínseca, caso as recompensas que o indivíduo busca ao desenvolver suas atividades fossem retiradas, a motivação diminuiria. Isso demonstraria que o envolvimento nas atividades ocorre com vista a um fim específico para se obter um determinado resultado, não havendo a presença de qualquer fator intrínseco. ${ }^{15}$ As recompensas extrínsecas são aquelas em que fazem parte das variáveis que desencadeiam o comportamento, são perfeitamente identificadas e fornecidas pelo meio ambiente, podendo-se citar os salários, dentre outros benefícios monetários, e resultam em motivação extrínseca porque proporcionam uma satisfação 


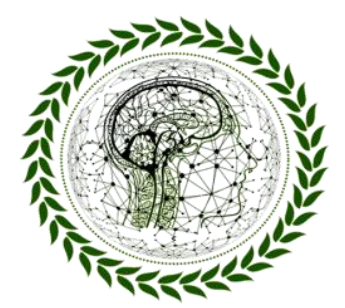

PhI Scientific Review

ISSN 2676 - (1444

independentemente da tarefa propriamente dita, bem como são controladas por outrem que não o próprio indivíduo. ${ }^{16}$

No contexto escolar há indicadores de que a motivação intrínseca facilita a aprendizagem e o desempenho dos estudantes. O estudante intrinsecamente motivado envolve-se em atividades que oferecem a oportunidade para o aperfeiçoamento de seus conhecimentos e de suas habilidades. Segundo Guimarães (2001) a motivação intrínseca refere-se à escolha e realização de determinada atividade por conta própria, ou seja, o comprometimento por tal tarefa é espontâneo, não sendo necessárias pressões externas para a sua execução. Por sua vez, o indivíduo extrinsecamente motivado, realiza uma tarefa escolar para melhorar suas notas ou para conseguir prêmios e elogios. ${ }^{17,18}$

Motivar, então, significa incentivar uma pessoa para a ação, para a realização e conquista das metas e objetivos, de modo a evitar a acomodação do indivíduo para que sempre prevaleça a criatividade. $^{19}$

Pela dimensão da TAD foram elaborados questionários baseados na Teoria da Autodeterminação, destacando-se o Inventário da Motivação Intrínseca (IMI), instrumento de medida multidimensional que avalia a experiência subjetiva dos participantes relacionada à realização de determinada tarefa. Foi usado em vários experimentos relacionados à motivação intrínseca e autorregulação. O instrumento avalia o interesse e aproveitamento dos participantes, durante a realização das atividades, gerando assim sete escores de subescala. ${ }^{20} \mathrm{~A}$ teoria da autodeterminação (SDT) foi elaborada no ano de 1981 por Richard M. Ryan e Edward L. Deci, no qual, definem que a teoria da autodeterminação se baseia em três necessidades básicas que auxiliam os indivíduos na tomada de decisão. A primeira necessidade básica é a de competência, a segunda é a de autonomia e o terceiro vínculo social. A competência pessoal está relacionada à adaptação ao ambiente e se refere à aprendizagem de um modo geral e também ao desenvolvimento cognitivo, autonomia é definida como o imperativo de ações e decisões em conformidade com os valores pessoais e com um nível alto de reflexão e consciência, e o vínculo 


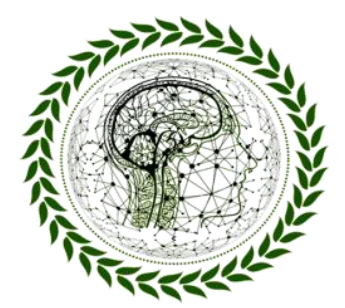

PhI Scientific Review

ISSN 2676 - (1444

social origina-se a procura por relacionamentos com outras pessoas, grupos ou comunidades, em busca da atividade de amar e ser amado. ${ }^{21}$

O IMI é composto por 45 itens do tipo Likert com sete níveis de respostas, contendo sete subescalas/domínios: interesse/prazer, competência percebida, esforço/importância, pressão/tensão, escolha percebida, valor/utilidade e integração (relacionamento). A subescala de interesse/prazer é considerada a medida de autor relato da motivação intrínseca. As subescalas de competência percebida e de escolha percebida são preditores positivos da motivação intrínseca, e a subescala de pressão/tensão é um preditor negativo. A subescala de esforço/importância é relevante para a motivação, e a de valor/utilidade traduz a ideia de que as pessoas internalizam e se tornam autorreguladoras em relação às atividades que elas consideram úteis ou valiosas para si mesmas; já a subescala de integração refere-se a interações interpessoais e formação de amizades. Esse instrumento foi traduzido e adaptado transculturalmente do inglês para o português do Brasil. $^{20,22}$

Por fim, analisar a motivação intrínseca baseada na Teoria da Autodeterminação dos estudantes é o ponto chave para uma observação mais fidedigna relacionada ao método ABP. ${ }^{23} \mathrm{O}$ objetivo deste trabalho é analisar a motivação intrínseca, baseada na Teoria da Autodeterminação, dos estudantes de Nutrição de uma faculdade pernambucana que utiliza a metodologia ABP, trazendo contribuições para a compreensão do método, o que permite um melhor desenvolvimento do processo de aplicação nas mais diversas áreas do conhecimento.

\section{MATERIAIS E MÉTODOS}

\section{Aspectos éticos}

Foram adotados os devidos termos, respeitadas suas singularidades, após esclarecimento sobre a natureza da pesquisa, justificativa, objetivos, métodos, potenciais benefícios e riscos aos participantes. Foi esclarecida a total liberdade do voluntário da pesquisa em recusar-se a 


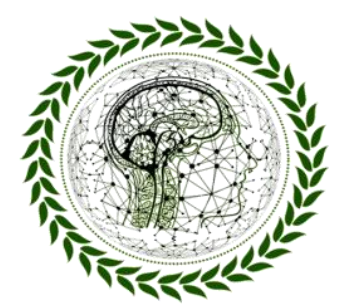

PhI Scientific Review

ISSN 2676 - (144

participar. Ademais, antes do início do preenchimento de cada questionário, foi apresentado aos sujeitos de pesquisa o Termo de Consentimento Livre e Esclarecido (TCLE), que deveria ser assinado após informação fornecida pelas pesquisadoras, explicando os objetivos, os métodos utilizados, os riscos e os eventuais benefícios individuais ou coletivos do estudo, foram esclarecidas, ainda, as dúvidas porventura existentes.

O estudo foi aprovado pelo Comitê de Ética em Pesquisa da Faculdade Pernambucana de Saúde (CEP-FPS), CAAE No 10112419.3.0000.5569.

\section{Tipo e local do estudo}

O estudo do tipo corte longitudinal foi realizado com os estudantes matriculados no curso de nutrição da Faculdade Pernambucana de Saúde (FPS), localizada em Recife - PE, no semestre 2019.2. A FPS utiliza a Aprendizagem Baseada em Problemas (ABP) como metodologia de ensino, na qual os estudantes, auxiliados pelo Tutor, discutem e analisam casos-problema. Esse momento, chamado grupo tutorial, ocorre em dois encontros semanais, com os seguintes passos: no primeiro momento, identificação de termos desconhecidos no texto, definição do problema do caso, tempestade de ideias, revisão dos passos anteriores e definição dos objetivos de aprendizagem; em seguida, o estudo dirigido, realizado entre os encontros; e, finalmente, o fechamento do caso numa discussão, no qual, refere-se à tutoria. ${ }^{24} \mathrm{~A}$ coleta de dados ocorreu nos meses de agosto e dezembro de 2019 (início e final de semestre letivo), sendo aplicado o Inventário de Motivação Intrínseca (IMI) como instrumento para análise da motivação relacionada ao grupo tutorial no método ABP. (Anexo I)

\section{População}

Foi composta por discentes do curso de Nutrição da FPS do $1^{\circ}$ ao $6^{\circ}$ período, no qual as matrizes curriculares se constituem por quatro eixos temáticos; Nutrição e desenvolvimento 


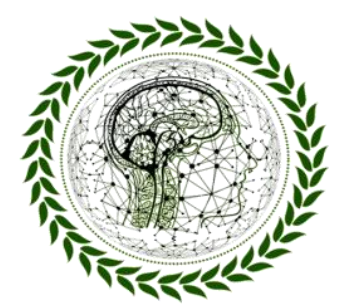

PhI Scientific Review

ISSN 2676 - 0444

saudável; Nutrição no processo saúde-doença; Qualidade dos alimentos; Ética na gestão, ensino e pesquisa, com carga horária modular (teórico/prática) de 2.296 horas. Como critério de inclusão a amostra foi composta por estudantes que realizam a tutoria, (do $1^{\circ}$ ao $6^{\circ}$ período) visto que, o intuito foi de avaliar a motivação intrínseca correlacionando aos períodos efetivos de tutorias na FPS. E o critério de exclusão foram os estudantes do $7^{\circ}$ e $8^{\circ}$ períodos, pois são períodos em que os estudantes realizam estágios curriculares obrigatórios do curso. O número total de estudantes matriculados no curso de nutrição no início do semestre foi de 177 , destes 159 responderam o questionário no primeiro momento da pesquisa, e ao final do semestre, 167 estudantes estavam matriculados no curso e 112 estudantes responderam o questionário no segundo momento da pesquisa. O tamanho da amostra demonstrou ser representativo, no qual, no primeiro momento $89,8 \%$ dos estudantes participaram e ao segundo momento $67,06 \%$ dos estudantes participaram, atingindo $>50 \%$ dos estudantes, cálculo da representatividade feito por regra de três.

\section{Aplicação do Inventário de Motivação Intrínseca (IMI)}

Para a coleta de dados foi utilizado o Inventário de Motivação Intrínseca, validado para a língua portuguesa em 2016, composto por 45 itens, tipo Likert, com 7 níveis de respostas, distribuídos em 7 subescalas: interesse/prazer, competência percebida, esforço/importância, pressão/tensão, percepção de escolha e integração (relacionamento) e valor/utilidade, estudada como variável numérica contínua (escore médio) e categórica nominal. Em relação ao IMI, inicialmente foi realizada a análise das respostas em espelho, considerando a existência do escore reverso em 16 questões de acordo com os seguintes domínios: interesse/prazer (questões 3 e 4), competência percebida (questão 13), esforço/importância (questões 15 e 18), pressão/tensão (questões 19 e 21), percepção de escolha (questões 25, 26, 27, 28 e 30) valor/utilidade (não existia questão de escore reverso) e integração (relacionamento) (questões 38, 39, 42 e 43). ${ }^{25}, 26$

Em seguida, cada subescala/domínio foi definida por meio da média aritmética do conjunto de itens que a compunha. Foram consideradas as sete opções de respostas (1 a 7), que 


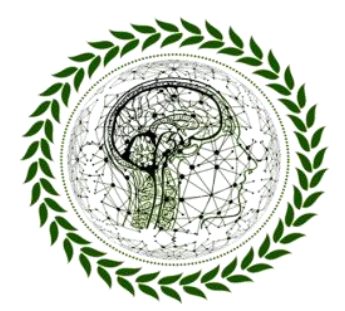

PhI Scientific Review

ISSN 2676 - (144

variavam de 1 =não verdadeiro, $4=$ algo verdadeiro a $7=$ muito verdadeiro, para definição da gradação dos escores. Sendo assim, foram originados e utilizados os seguintes pontos de corte: $\leq 3,0$ (não verdadeiro/não motivado), $>3,0$ e $<6,0$ (algo verdadeiro/motivado) e $\geq 6,0$ (muito verdadeiro/muito motivado), conforme foi relatado o ponto médio no trabalho de Pedro et. al. ${ }^{20}$ Como desfecho, para fins de análise estatística, foi considerado a motivação intrínseca categorizada em $\operatorname{sim}(>3,0)$ e não $(\leq 3,0)$.

As coletas foram realizadas no início do semestre letivo, durante duas semanas consecutivas, ao final da exposição dos casos, no horário entre8he8h10min. O tempo médio de 10 minutos foi reservado para esclarecimentos, assinatura do TCLE e preenchimento das perguntas do IMI.

O quantitativo de matriculados, do $1^{\circ}$ ao $6^{\circ}$ período no início do semestre, seguiu a seguinte distribuição, 24 do $1^{\circ}$ período, 33 do $2^{\circ}$ período, 22 do $3^{\circ}$ período, 41 do $4^{\circ}$ período, 22 do $5^{\circ}$ período e 35 do $6^{\circ}$ período. Foi coletado um total de 20 inventários do $1^{\circ}$ período, 30 inventários do $2^{\circ}$ período, 17 inventários do $3^{\circ}$ período, 35 inventários do $4^{\circ}$ período, 22 inventários do $5^{\circ}$ período e 35 inventários do $6^{\circ}$ período, totalizando 159 estudantes. Nesse primeiro momento foi utilizado o questionário impresso, sendo distribuídos aos estudantes, consoante forma de apresentação disponível no Anexo I.

O segundo momento de aplicação do Inventário de Motivação Intrínseca (IMI) conteceu nas últimas duas semanas do calendário acadêmico, novamente com estudantes do $1^{\circ}$ ao $6^{\circ}$ períodos do curso. A relação de matriculados ao final do semestre foi de 19 estudantes no $1^{\circ}$ período, 23 estudantes no $2^{\circ}$ período, 22 estudantes no $3^{\circ}$ período, 45 estudantes no $4^{\circ}$ período, 23 estudantes no $5^{\circ}$ período e 35 estudantes no $6^{\circ}$ período, atingindo um total de 167 estudantes, no qual participaram 112 estudantes. Nesse segundo momento foi utilizado um meio digital para a coleta de dados, através do aplicativo Forms com leitura por QR Code, que consiste em um gráfico 2D, lido por meio de aparelhos celulares.Foi disponibilizado, ainda, como segunda opção, o link do questionário para os participantes que apresentassem alguma dificuldade de acesso, disponível no Anexo II.

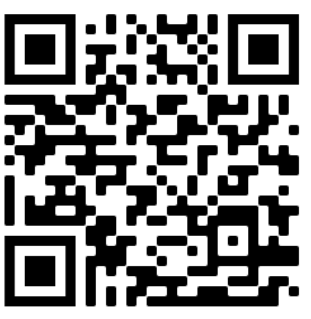

http://www.revistaphd.periodikos.com.br

V. 02, $\mathrm{N}^{\mathrm{o}}$ 01, janeiro de 2022

DOI: $10.53497 /$ phdsr2n1-001

Todos os direitos reservados $(\mathrm{C}$ 


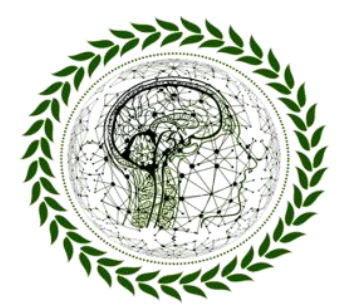

PhD Scientific Review

ISSN 2676 - (1444

\section{Análise de dados}

Os dados foram computados no Programa $\mathrm{R}$ versão 3.4.3. As variáveis contínuas estudadas foram apresentadas através da média e desvio padrão (DP). Os dados categóricos sendo eles variáveis não numéricas; interesse/prazer; competência percebida; valor/utilidade; esforço/importância; pressão/tensão; percepção de escolha; e integração, foram descritos através de tabelas de distribuição de frequências digitados no programa Excel. Considerou-se como categoria de referência aquela cujo desfecho apresentou maior frequência (motivação intrínseca com escore médio $>3$ ). Nesta etapa da análise de dados, para fins estatísticos, permaneceram no modelo final as variáveis com valor $\mathrm{p}<0,05$, sendo considerada diferença significativa o $\mathrm{p}$-valor menor que 0,05 . Foi realizada a correlação entre subescala e períodos.

\section{RESULTADOS E DISCUSSÃO}

Dos 177 estudantes matriculados no início do semestre, foram recolhidos 159 questionários. Não foi possível realizar a coleta inicial com a totalidade de estudantes regularmente matriculados no início do semestre, ressaltando que não havia obrigatoriedade de participação. Por outro lado, houve uma diminuição na coleta do final do semestre, com 167 estudantes matriculados e 112 questionários coletados.

Considerando os fatores que influenciam a motivação intrínseca do estudante, foi comparada a motivação dos estudantes dos primeiros períodos do curso $\left(1^{\circ}, 2^{\circ}\right.$ e $\left.3^{\circ}\right)$ e dos últimos períodos $\left(4^{\circ}, 5^{\circ}\right.$ e $\left.6^{\circ}\right)$. Os escores por domínio e de acordo com os períodos encontram-se na tabela 1.

Tabela 1. Escores médios da motivação intrínseca dos estudantes em grupo tutorial do curso de Nutrição nos períodos iniciais e finais do curso

\begin{tabular}{|c|c|c|c|}
\hline \multirow{2}{*}{ Subescala } & \multicolumn{2}{|c|}{ Escores médios de motivação intrínseca* } & \multirow[b]{2}{*}{ P-valor } \\
\hline & $1^{\circ} 2^{\circ}$ e $3^{\circ}$ período & $4^{\circ} 5^{\circ}$ e $6^{\circ}$ período & \\
\hline & Média \pm DP & Média \pm DP & \\
\hline
\end{tabular}




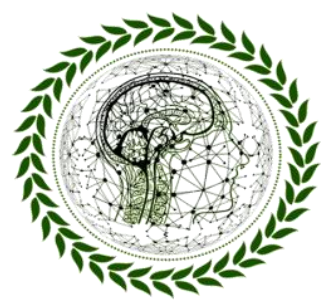

PhI Scientific Review

ISSN 2676 - 0444

$\begin{array}{llll}\text { Interesse/prazer } & 5,6 \pm 1,0 & 5,5 \pm 1,2 & 0,96 \\ \text { Competência percebida } & 5,0 \pm 1,1 & 5,0 \pm 1,2 & 0,98 \\ \text { Valor/utilidade } & 6,3 \pm 1,0 & 6,1 \pm 1,5 & 0,20 \\ \text { Esforço/importância } & 5,4 \pm 1,3 & 5,1 \pm 1,3 & 0,19 \\ \text { Pressão/tensão } & 4,0 \pm 1,6 & 4,4 \pm 1,6 & 0,19 \\ \text { Percepção de escolha } & 5,0 \pm 0,9 & 5,0 \pm 1,0 & 0,96 \\ \text { Integração } & 5,5 \pm 1,0 & 5,8 \pm 0,8 & 0,10\end{array}$

$* \leq 3,0$ (não motivado), $>3,0$ e $<6,0$ (motivado) e $\geq 6,0$ (muito motivado).

A subescala de valor/utilidade, considerando todos os períodos, apresentou escore maior que 6,0, demonstrando que os alunos se mostraram muito motivados. Essa escala incorpora à ideia que as pessoas internalizem e desenvolvam mais atividades de autoregulação quando a experiência é considerada valiosa e útil para eles.

Comparando com um estudo no quais foram avaliadas as propriedades psicométricas do IMI em estudantes portugueses, testando quatro modelos de organização, foram constatadas que a versão em português do IMI mostrou validade e confiabilidade adequadas para a avaliação de motivação intrínseca em Língua Portuguesa e Matemática, sendo também um instrumento confiável. Nessa mesma perspectiva a autorregulação designa um conjunto de pensamentos, sentimentos e ações geradas pelos alunos para atingir objetivos educativos específicos. ${ }^{27,28}$

Nas demais subescalas, considerando todos os períodos, as médias ficaram entre 4,0 e 5,8, demonstrando que os estudantes estavam motivados classificado em "motivado" $>3,0$ e $<6,0$ e $\geq 6,0$ "muito motivado". Na subescala competência percebida, teorizado como preditor positivo da motivação intrínseca, foi observado que, dentro do ponto de corte estipulado em nosso estudo $(>3,0)$ do $1^{\circ}$ ao $6^{\circ}$ período todos os estudantes se sentiram competentes em realizar as atividades. Observou-se que no começo do semestre, em geral, os estudantes mostraram-se motivados, independentemente dos períodos comparados, não havendo diferenças significativas entre eles. 


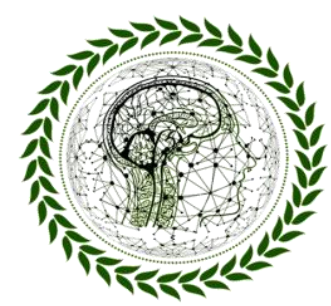

PhI Scientific Review

ISSN 2676 - (144

As subescalas de competência percebida e de percepção de escolha são preditores positivos, sendo relacionadas à TAD psicológica e inata, associando com suas necessidades de autonomia e competência, nesse sentido, de acordo com Pedro Tadeu e colaboradores (2019), em pesquisa feita com estudantes de medicina, demonstrou que para competência percebida, todos os estudantes do $2^{\circ}, 6^{\circ}$ e $10^{\circ}$ períodos, no cenário estudado, se percebem competentes. As demais subescalas também se destacaram os quais apresentaram valores interesse/prazer como média geral 3,9, competência percebida 3,9, esforço/importância 3,6, pressão/tensão 2,9, escolha percebida 2,5, valor utilidade 6,0 e integração 3,3. Esses achados se assemelham com o presente estudo com a ressalva que dois domínios apresentaram escores $<3$ entre a avaliação dos estudantes, sendo eles pressão/tensão e escolha percebida. No presente estudo, para todas as subescalas avaliados foram atribuídas notas $>3 .{ }^{26}$

Quanto à subescala pressão/tensão, considerada preditora negativa, a média de todos os escores foi 4,2. Presume-se que mesmo sendo uma preditora negativa, os estudantes avaliam como um ponto positivo para o método.

Verificando os gráficos no início do semestre, temos a motivação dos estudantes por período e a correlação entre as subescalas (Gráficos $1^{\circ}$ ao $\left.7^{\circ}\right)$.

Gráfico 1. Correlação entre a subescala competência e período do curso

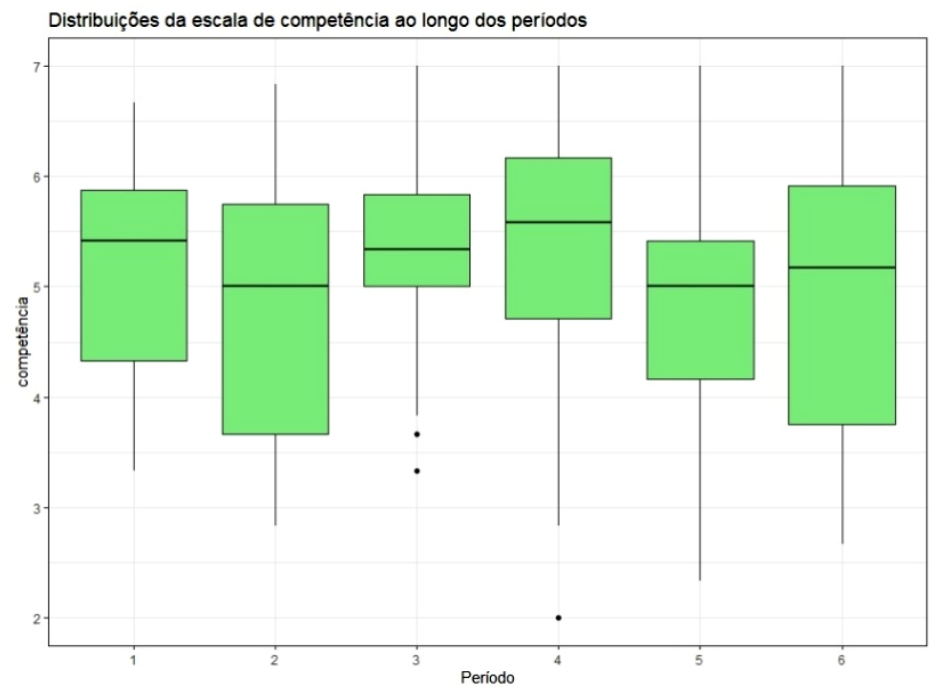




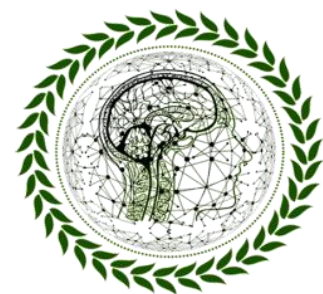

PhI Scientific Review

ISSN 2676 - (1444

Gráfico 2. Correlação entre a subescala integração e período do curso

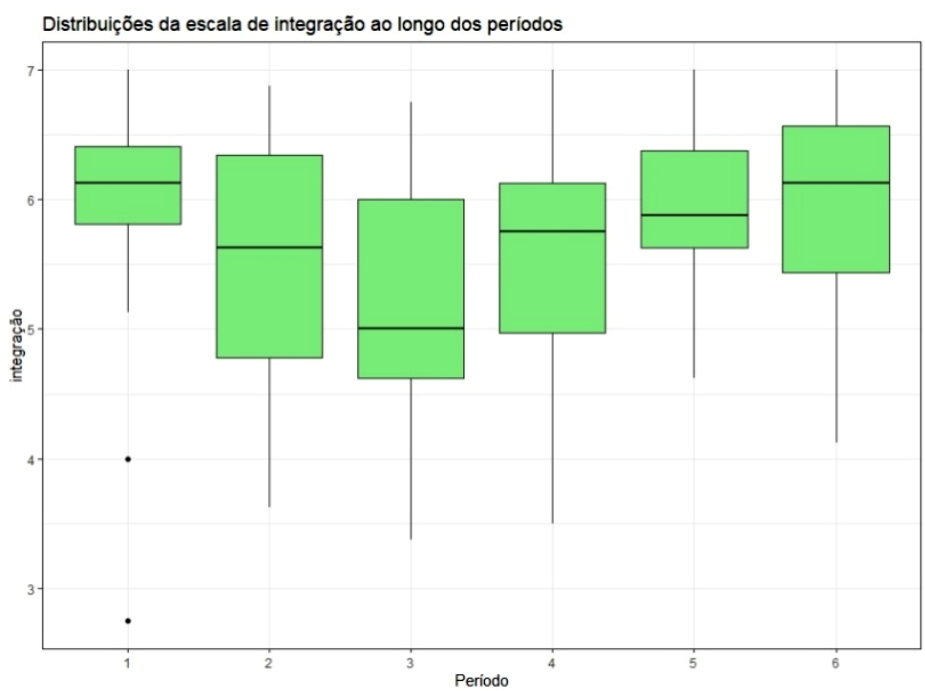

Gráfico 3. Correlação entre a subescala interesse e período do curso.

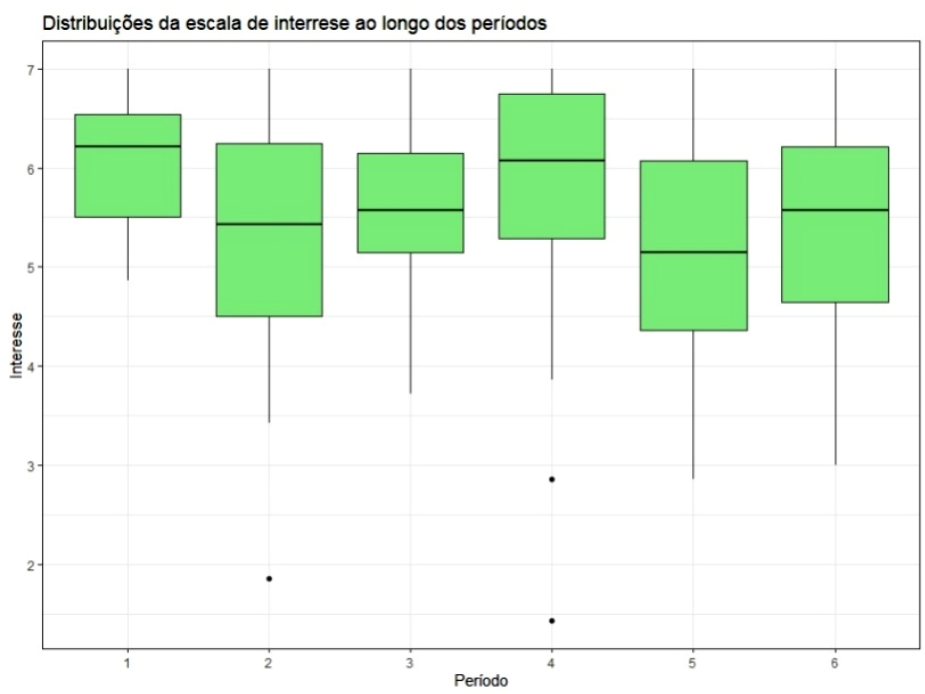




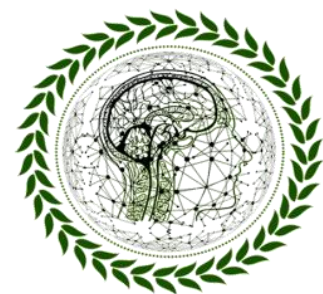

PhI Scientific Review

ISSN 2676 - (1444

Gráfico 4. Correlação entre a subescala pressão e período do curso

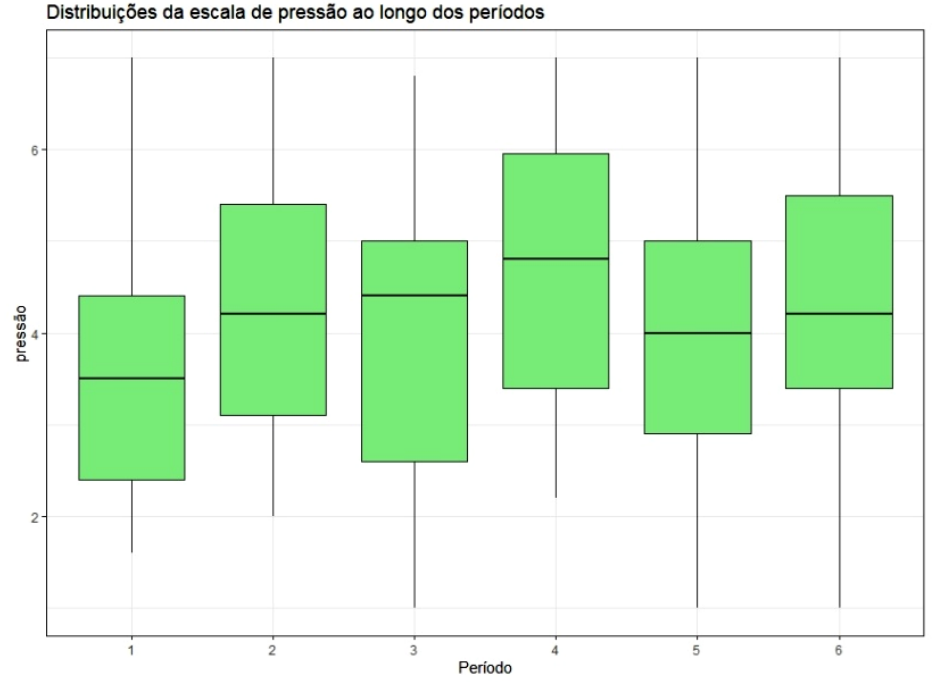

Gráfico 5. Correlação entre a subescala esforço e período do curso

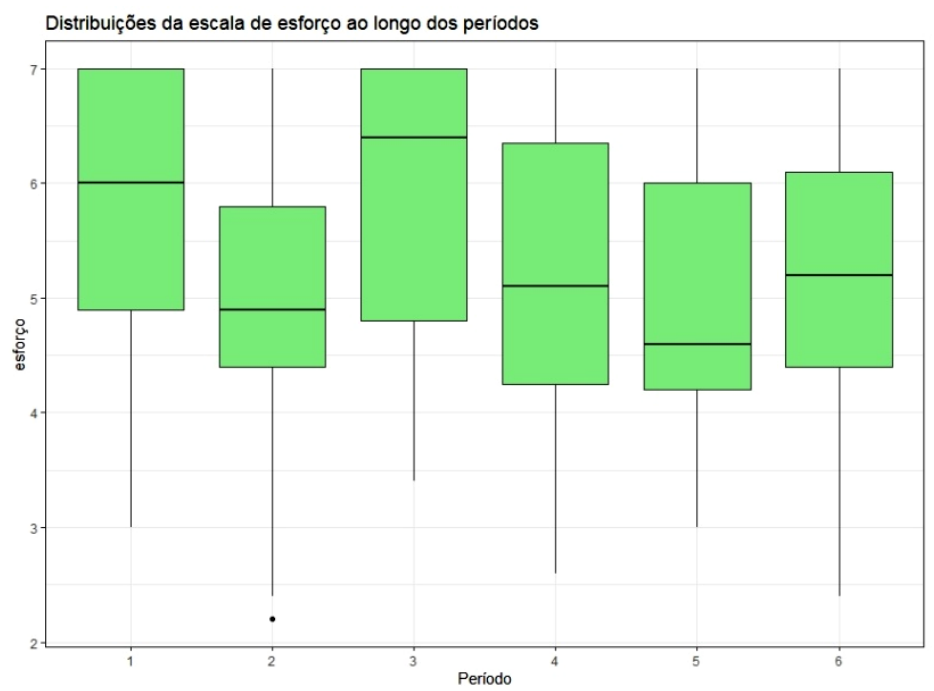




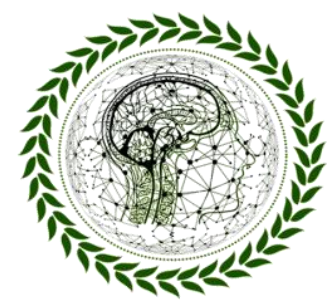

PhI Scientific Review

ISSN 2676 - 1444

Gráfico 6. Correlação entre a subescala valor e período do curso

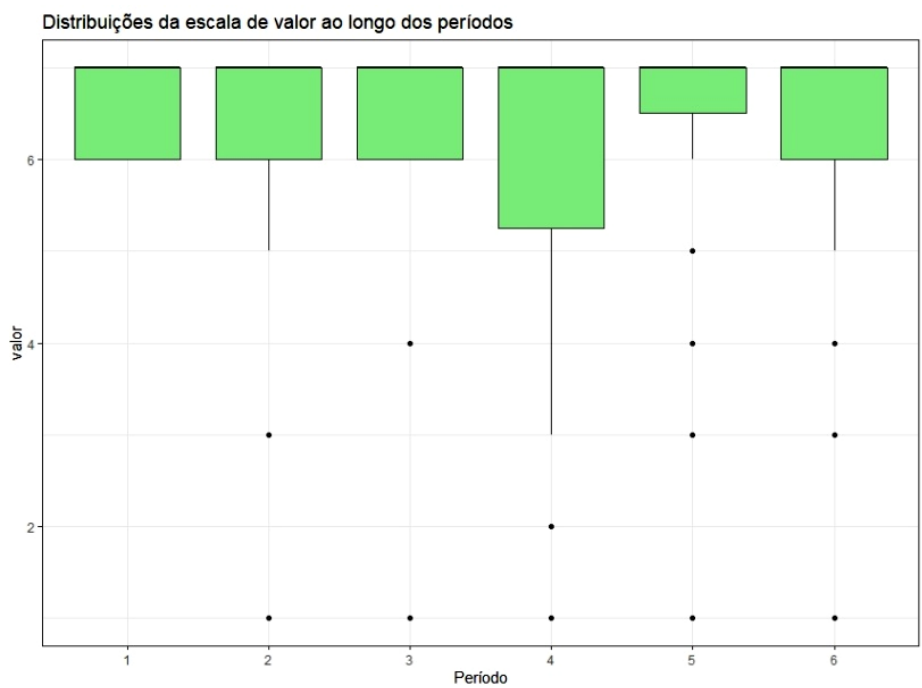

Gráfico 7. Correlação entre a subescala percepção e período do curso

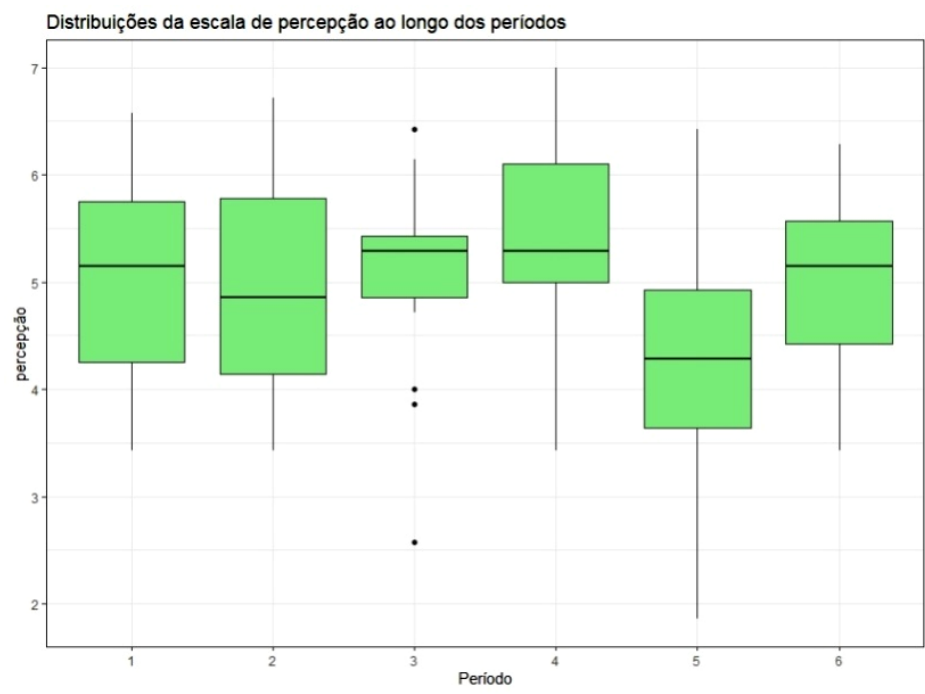

Os gráficos apresentam a distribuição dos valores, podendo-se afirmar que há correlação entre as variáveis, a correlação entre os períodos e as subescalas integração e pressão/tensão foi 


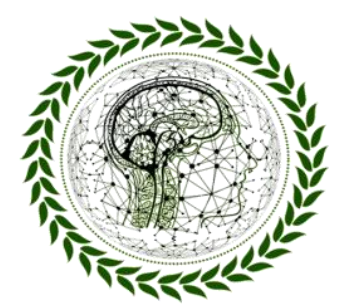

PhI Scientific Review

ISSN 2676 - (144

positiva (Gráficos 2 e 4), ou seja, a medida que o período aumenta estas subescalas aumentam, sendo a correlação entre as variáveis integração-período mais forte. A subescala integração refere-se às relações interpessoais, no qual, podemos referir que à medida que o período aumenta ás relações interpessoais entre os discentes aumentam, essa subescala ocorre a partir do convívio com seu grupo tutorial dando sequência ao aprendizado que ocorre a partir da apresentação de problemas, reais ou simulados, a um grupo de alunos. ${ }^{19}$ Os alunos, recorrem aos conhecimentos prévios, discutem, estudam, adquirem e integram os novos conhecimentos.

As subescalas competência percebida, interesse/prazer, esforço/importância, valor/utilidade e percepção de escolha (Gráficos 1, 3, 5, 6, e 7) apresentaram correlação negativa.

O método ABP contempla os três pilares básicos da TAD (autonomia, competência e estabelecimento de vínculos) o que foi constatado nesta pesquisa, cujos estudantes avaliados se mostraram intrinsecamente motivados, diante das médias das subescalas apresentadas. ${ }^{22,29,30}$ Portanto, o método ABP valoriza, além do conteúdo a ser aprendido, a forma como ocorre o aprendizado, reforçando o papel ativo de todos os estudantes neste processo, permitindo que eles entendam como aprender, contribuindo, assim, com o seu grupo tutorial, facilitando o domínio como um todo, onde todos se ajudam. ${ }^{31}$

Os resultados dos dados de final do semestre, escores por subescala, de acordo com todos os períodos estão apresentados na tabela 3 .

Tabela 3. Escores médios da motivação intrínseca dos estudantes de Nutrição no final do semestre

\begin{tabular}{lc}
\hline Subescala & $\begin{array}{c}\text { Escores médios de motivação intrínseca* } \\
1^{\circ}, 2^{\circ}, 3^{\circ}, 4^{\circ}, 5^{\circ} \text { e } 6^{\circ} \text { período } \\
\text { Média } \pm \text { DP }\end{array}$ \\
\hline Interesse/prazer & $5,3 \pm 1,1$ \\
Competência percebida & $5,3 \pm 1,1$ \\
Valor/utilidade & $6,1 \pm 1,3$ \\
Esforço/importância & $5,0 \pm 1,2$ \\
Pressão/tensão & $4,3 \pm 1,6$ \\
Percepção de escolha & $4,7 \pm 1,2$
\end{tabular}

http://www.revistaphd.periodikos.com.br

V. 02, $\mathrm{N}^{\mathrm{o}}$ 01, janeiro de 2022

DOI: $10.53497 /$ phdsr2n1-001

Todos os direitos reservados(C) 


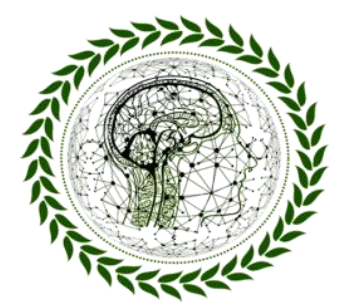

PhI Scientific Review

ISSN 2676 - 0444

Integração

$5,4 \pm 1,0$

$* \leq 3,0$ (não motivado), $>3,0$ e $<6,0$ (motivado) e $\geq 6,0$ (muito motivado).

A subescala de valor/utilidade ao final do semestre apresentou escore 6,1, expressando que os estudantes se mostraram muito motivados. Nas demais subescalas, as médias ficaram entre 4,3 e 5,4 demonstrando que os alunos estavam motivados ao final do semestre.

Podemos associar a motivação dos estudantes deste estudo com um estudo realizado com estudantes de Fisioterapia em uma faculdade particular de São Paulo, no qual se relacionava com motivação dos estudantes no início do curso e ao final do curso, como resultado obteve-se que a comparação da pontuação obtida para os itens da motivação intrínseca e extrínseca foi realizada para os dois grupos, não havendo significância estatística para os ingressantes ou concluintes. Esses achados sugerem que as expectativas dos graduandos em nutrição, participantes do presente estudo, sejam eles ingressantes ou concluintes, estão sendo atendidas nas duas fases, fazendo-os estar motivado intrinsecamente para a atividade do grupo tutorial. ${ }^{32}$

A motivação intrínseca dos estudantes do $1^{\circ}$ ao $6^{\circ}$ período foi comparada os escores por domínio, no início e final do semestre (Tabela 4).

Tabela 4. Escores médios da motivação intrínseca dos estudantes de Nutrição do início e final de semestre.

\begin{tabular}{|c|c|c|c|}
\hline \multirow[t]{3}{*}{ Domínio } & \multicolumn{3}{|c|}{ Escores médios de motivação intrínseca* } \\
\hline & & Final semestre & \multirow{2}{*}{ P-valor } \\
\hline & Média \pm DP & Média \pm DP & \\
\hline Interesse/prazer & $5,5 \pm 1,1$ & $5,3 \pm 1,1$ & 0,09 \\
\hline Competência percebida & $5,1 \pm 1,1$ & $5,3 \pm 1,1$ & 0,16 \\
\hline Valor/utilidade & $6,2 \pm 1,3$ & $6,1 \pm 1,3$ & 0,42 \\
\hline Esforço/importância & $5,2 \pm 1,3$ & $5,0 \pm 1,2$ & 0,14 \\
\hline Pressão/tensão & $4,2 \pm 1,6$ & $4,3 \pm 1,6$ & 0,34 \\
\hline Percepção de escolha & $5,0 \pm 0,9$ & $4,7 \pm 1,2$ & $0,02 * *$ \\
\hline Integração & $5,7 \pm 0,9$ & $5,4 \pm 1,0$ & $0,01 * *$ \\
\hline
\end{tabular}




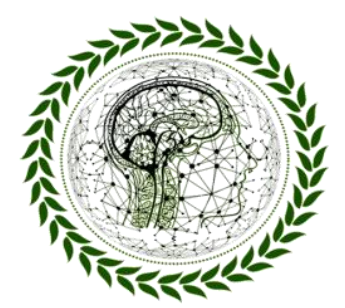

\section{PhI Scientific Review}

ISSN 2676 - 0444

A subescala de valor/utilidade, considerando o início e o final de semestre, apresentou escore maior que 6,0, demonstrando que os alunos se mostraram muito motivados. No domínio interesse/prazer, de acordo com esta pesquisa, os alunos demonstram-se interessados por essa atividade do grupo tutorial, com uma média de escore 5,4, no qual consideramos motivados para realização da atividade. No domínio competência percebida 5,2, esforço importância 5,1, pressão/tensão 4,2, percepção de escolha 4,8 e integração 5,5. Sendo assim, os estudantes, em geral, se mantiveram motivados no decorrer de todos os períodos subsequentes. Nas subescalas percepção de escolha e integração houve valores significativos $(p<0,05)$ demonstrando diferenças quando comparados início e fim do semestre para todos os períodos, ou seja, no segundo semestre os estudantes se mostraram menos motivados em relação a essas subescalas.

Associando com o método ABP, um estudo feito com estudantes de Medicina no qual foi conduzido em duas escolas de Medicina: uma com metodologia ABP e outra com metodologia tradicional, avaliando a auto eficácia acadêmica de estudantes relacionando-se com sua capacidade de organizar e executar ações relacionadas às atividades e exigências acadêmicas, os dados quando comparados demostram que os estudantes do $4^{\circ}$ ano das instituições analisadas apresentaram auto eficácia de moderada a forte. Os estudantes da escola da ABP apresentaram escores de auto eficácia maiores em relação aos da escola com metodologia tradicional indicando que o uso de metodologia ativa de ensino, como a do modelo ABP, pode se relacionar a um maior grau de auto eficácia acadêmica. ${ }^{33}$ Reforçando assim, a importância do método no cenário atual, influenciando positivamente os estudantes quanto à sua motivação intrínseca e a execução das atividades propostas no processo de ensino-aprendizagem.

\section{CONCLUSÕES}

O presente estudo concluiu que os estudantes de Nutrição se apresentaram intrinsecamente motivados para realizar as atividades no grupo tutorial, tanto em períodos iniciais quanto nos períodos finais do curso, não havendo diferença significativa entre eles. A partir da 


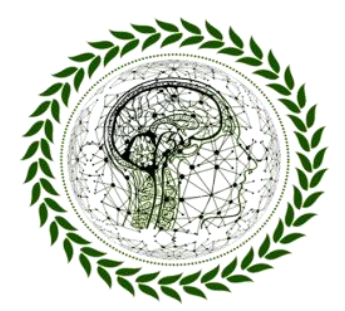

\section{PhI Scientific Review \\ ISSN 2676 - 0444}

avaliação das subescalas, observou-se destaque para a média de nota da subescala valor/utilidade, a qual demonstrou que os alunos estavam "muito motivados" e as demais avaliações das subescalas apresentadas demonstraram que os alunos estão motivados. É possível concluir que os estudantes de nutrição envolvidos no estudo encontraram-se intrinsecamente motivados durante a atividade no grupo tutorial, realizada na metodologia da ABP.

\section{REFERÊNCIAS BIBLIOGRÁFICAS}

01. GARCIA, M. B. O.; OLIVEIRA, M. M.; PLANTIER, A. P. Interatividade e Mediação na Prática de Metodologia Ativa: o Uso da Instrução por Colegas e da Tecnologia na Educação Médica. Revista Brasileira de Educação Médica, v. 43, n. 1, p. 87-96, 2019.

02. SIMON, E. et al. Metodologias ativas de ensino-aprendizagem e educação popular: encontros e desencontros no contexto da formação dos profissionais de saúde. Interface-Comunicação, Saúde, Educação, v. 18, p. 1355-1364, 2014.

03. DEWEY, How we think. Toronto, Canadá. Kobo Editions, 2016

04.JÚNIOR, E. A. et al. O uso de metodologias ativas na prática de monitoria acadêmica no curso de medicina: aprendizado baseado em problemas/The use ofactive methodologies in academic monitoring practice in medicine course: learning based on problems. Brazilian Journal of Development, v. 5, n. 11, p. 26281-26285, 2019.

05. BACICH, L.; MORAN, J. Metodologias ativas para uma educação inovadora: uma abordagem téorico-prática. Porto Alegre: Penso. 2018.

06. MAMEDE, S.; PENAFORTE, J. (Org.). Aprendizagem baseada em problemas: anatomia de uma nova abordagem educacional. Fortaleza: Hucitec, 2001. p. 25-48.

07. DELISLE, R. Como realizar a Aprendizagem Baseada em Problemas. Porto: ASA, 2000.

08. LAMBROS. Problem-Based Learning in Middleand High School Classrooms - A Teacher's Guide to Implementation. Thousand Oaks: Corwin Press, Inc. 2004.

09. BEZERRA, I. N. M. et al. A utilização da aprendizagem baseada em problema (abp) na formação em saúde: um relato de experiência. Revista Ciência Plural, v. 6, n. 1, p. 102-118, 2020.

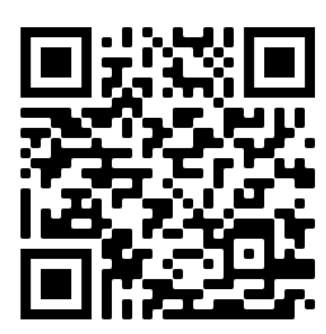

http://www.revistaphd.periodikos.com.br

V. 02, $\mathrm{N}^{\mathrm{o}}$ 01, janeiro de 2022

DOI: 10.53497/phdsr2n1-001

Todos os direitos reservados(C) 


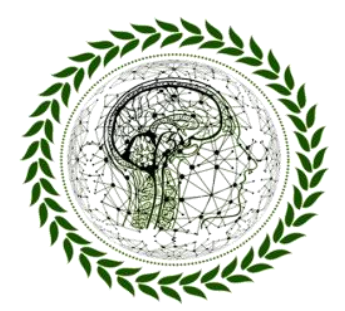

PhI Scientific Review

ISSN 2676 - 1044

10. RONN, A. P. et al. Evidências da efetividade da aprendizagem baseada em problemas na educação médica: uma revisão de literatura. Revista Ciência e Estudos Acadêmicos de Medicina, v. 1, n. 11, 2019.

11. VASCONCELOS COLARES, A. C. et al. Motivação docente na pós-graduação stricto sensu: uma análise a partir da teoria da autodeterminação. Revista Contabilidade \& Finanças-USP, v. 30, n. 81, 2019.

12. BORGES, M. S.; MIRANDA, G. J.; FREITAS, S. C.. A teoria da autodeterminação aplicada na análise da motivação e do desempenho acadêmico discente do curso de ciências contábeis de uma instituição pública brasileira. Revista Contemporânea de Contabilidade, v. 14, n. 32, p. 89107, 2017.

13. RYAN, R. M.; DECI, E. L. Intrinsicandextrinsicmotivations: Classic definitionsand new directions. Contemporary educational psychology, v. 25, n. 1, p. 54-67, 2000.

14. DECI, E. L. Effects of externally mediated rewards on intrinsic motivation. Journal of personality and Social Psychology, v. 18, n. 1, p. 105, 1971.

15. PIZANI, J. et al. (Des) motivação na educação física escolar: uma análise a partir da teoria da autodeterminação. Revista brasileira de ciências do esporte, v. 38, n. 3, p. 259-266, 2016.

16. LIRA, M.; DA SILVA, V. P. G. Motivação intrínseca vs. motivação extrínseca: A aplicação da Escala WPI no contexto do setor público português. Revista de Gestão, Finanças e Contabilidade, v. 5, n. 4, p. 171-195, 2015.

17. GUIMARÃES, Sueli ER. Motivação intrínseca, extrínseca e o uso de recompensas em sala de aula. A motivação do aluno: contribuições da psicologia contemporânea, v. 3, p. 37-57, 2001.

18. HENDERSON, V. L; DWEECK, C. S. Motivation and achievement. In: FELDMAN, S.; ELLIOT, G. R. (Org.). At the threshold: the developing adolescent. Boston: Harvard University, 1990. p.308-29.

19. GRIFFIN, Ricky W.; MOORHEAD, Gregory.Fundamentos do comportamento organizacional. São Paulo: Ática, 2006. 488p.

20. PEDRO TADEU ÁLVARES COSTA et. al. Motivação Intrínseca do Estudante de Medicina de uma Faculdade com Metodologia Ativa no Brasil: Estudo Transversal; Rev. bras. educ. med. vol. 43 no.1 supl. 1 Brasília 2019 


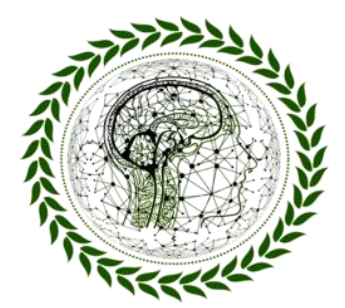

PhI Scientific Review

ISSN 2676 - (1)44

21. MARLI APPEL SILVA et. al A teoria da autodeterminação e as influências socioculturais sobre a identidade Psicol. rev.(Belo Horizonte) vol.16 no.2 Belo Horizonte ago. 2010

22. WOUTERS, Anouk et al. Motivation of Dutch high school students from various backgrounds for applying to study medicine: a qualitative study. BMJ open, v. 7, n. 5, p. e014779, 2017.

23. BARRETT, T.; MOORE, S. New approaches to problem-based learning: Revitalising your practice in higher education. Routledge, 2010.

24. MARTELA, F.; RYAN, R. M.; STEGER, M. F. Meaningfulness as satisfaction of autonomy, competence, relatedness, and beneficence: Comparing the four satisfactions and positive affect as predictors of meaning in life. JournalofHappinessStudies, v. 19, n. 5, p. 1261-1282, 2018.

25. ANDRADE, C. R. S. de; GODOY, C. G. de; MONTEIRO, R. L. S. Tradução e adaptação transcultural do inventário de motivação intrínseca para aplicação em estudantes de medicina. 2016.

26. AZEVEDO, PEDRO TADEU ÁLVARES COSTA CAMINHA et al. Motivação Intrínseca do Estudante de Medicina de uma Faculdade com Metodologia Ativa no Brasil: Estudo Transversal. Rev. bras. educ. med. [online]. 2019, vol.43, n.1, suppl.1, pp.12-23. Epub Jan 13, 2020.

27. MONTEIRO, V.; MATA, L.; PEIXOTO, F. Intrinsic motivation inventory: Psychometric properties in the context of first language and mathematics learning. Psicologia: Reflexão e Crítica, v. 28, n. 3, p. 434-443, 2015.

28. ZIMMERMAN, B. J. et al. Des apprenantsautonomes: autorégulation des apprentissages. De BoeckUniversité, 2000.

29. BURGESS, A.; VAN DIGGELE, C.; MELLIS, C. Students as facilitators in a teacher training program: motivation for leadership roles. Advances in medical educationandpractice, $\mathrm{v}$. 6, p. 615, 2015.

30. LUNA, W. F.; BERNARDES, J. de S. Tutoria como estratégia para aprendizagem significativa do estudante de Medicina. Revista Brasileira de Educação Médica, v. 40, n. 4, p. 653662, 2016.

31. JÚNIOR, A. C. C. T. et al. Aprendizagem baseada em problemas: uma nova referência para a construção do currículo médico. Revista Médica de Minas Gerais, v. 18, n. 2, p. 123-131, 2008.

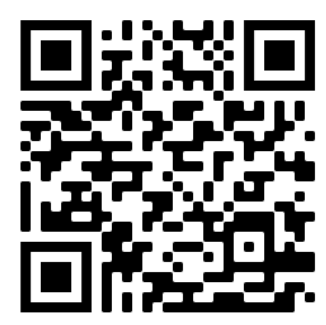

http://www.revistaphd.periodikos.com.br

V. 02, $\mathrm{N}^{\mathrm{o}} 01$, janeiro de 2022

DOI: $10.53497 /$ phdsr2n1-001

Todos os direitos reservados@ 


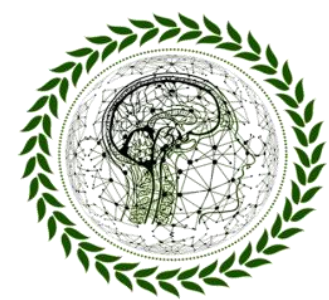

PhI Scientific Review

ISSN 2676 - 0444

32. BLASCOVI-ASSIS, S. M. Motivação na universidade: um estudo com estudantes de fisioterapia. Fisioterapia Brasil, v. 13, n. 1, p. 20-24, 2016.

33. LOPES, J. M. et al. Autoeficácia de Estudantes de Medicina em Duas Escolas com Metodologias de Ensino Diferentes (Aprendizado Baseado em Problemas versus Tradicional). Revista Brasileira de Educação Médica, v. 44, n. 2, 2020. 